\title{
Development of Glasgow Coma and Outcome Scales
}

\author{
Bryan Jennett, MD, FRCS \\ Professor Emeritus \\ University Department of \\ Neurosurgery \\ Institute of Neurological \\ Sciences \\ Glasgow, Scotland \\ United Kingdom
}

Address for correspondence: Bryan Jennett, MD, FRCS 3/3, 47 Novar Drive Glasgow G12 9UB

Scotland, UK

Email:

Bryan.jennett@ntlworld.com

Received, October 13, 2004 Accepted, October 14, 2004
These scales were developed primarily to facilitate the assessment and recording of initial severity of brain dysfunction and of ultimate outcome in a multicenter study of outcome after severe brain damage. The aim was to use simple terms that could be readily understood by a wide range of observers, including doctors, nurses and others. Repeated observations of the coma scale displayed on a bedside chart give it a second use - the monitoring of improvement or deterioration in conscious level as an indication of recovery or of complications. Early sedation and ventilation can make assessment difficult but the motor score alone is still a good guide to severity. Giving numbers to the level of response in the three components of the coma scale (eye opening, motor and verbal responses) facilitates communication between different staff, including those consulted by telephone. Adding up these scores to give an overall coma score (from 3 to 15) results in some loss of information but is useful for triage and for epidemiological studies. Even among mild injuries (coma score 13-15) the score discriminates between those more or less likely to develop complications. The outcome scale describes overall social function rather than neurological deficits, and is useful in monitoring recovery. The outcomes so described at six months after injury correlate well with the early coma scale scores, which are therefore useful predictors of likely outcome.

Key Words: acute brain damage, coma, conscious level, head injury, outcome, severity of brain dysfunction
Whenever there is an acute brain insult, whether from head injury or non-traumatic events such as stroke or poisoning for example, there is an immediate need to assess the degree of brain dysfunction. This determines what interventions are needed and provides a baseline from which to judge progress towards recovery or complications. The best measure of the overall brain dysfunction is the level of consciousness as assessed clinically. This also gives an early indication of the likely outcome - and the reliable measurement of this is essential both to discover the predictive value of early features and to validate comparisons made between alternative therapeutic regimes in the acute stage. The coma and outcome scales will be dealt with separately.

\section{Before the Glasgow Coma Scale}

Early in World War II the Medical Research Council in Britain issued a glossary of psychological terms commonly used in cases of head injury. ${ }^{13}$ It claimed that its use would facilitate the exchange of information between different observers as injured men were passed from one medical officer to another. The 16 terms included coma and semicoma, mild, moderate and severe confusion, as well as stupor and automatism. Unfortunately these were not easily defined and published reports on the treatment of war injuries seldom referred to the severity of brain dysfunction and those that did showed no evidence that the terms of the MRC glossary had been adopted.

Post-war neurosurgical practice was much more concerned with elective surgery for tumors and aneurysms and there was a fatalistic attitude to head injuries - believing that apart from elevating depressed fractures and evacuating the occasional intracranial hematoma little could be done to affect the outcome. However, as resuscitation and intensive care began to save the lives of many severely head injured patients neurosurgeons were challenged both to assist in reducing mortality and in saving as much of the damaged brain as possible in order to limit disability in survivors. Moreover pathological studies in Glasgow revealed that much of the mortality and persisting disability after head injury was potentially avoidable, as reflected in the title of one paper 'Head injuries who talk and die'. ${ }^{18}$ The implication was that if they had talked they had not suffered irreversible damage and should not have died. Many avoidable deaths resulted from failure to detect complications early enough for effective treatment. Meanwhile intensivists, concerned with the high rate of mortality and of disability in those that 
they treated wanted to know how to predict who was worth treating (or continuing to treat), and to assess the relative value of alternative regimes of management.

\section{The Coma Scale for Multicenter Studies}

These concerns led us in Glasgow in 1970 to set up studies of severe head injury with collaborators in the Netherlands and the USA. ${ }^{9}$ These were later extended to include the monitoring of early severity and of outcome of coma from non-traumatic brain insults. ${ }^{3}$ Comparisons were needed between groups of patients whose initial injuries were of similar (but varying) severity, and their outcome. As data collection and analysis was to involve computers the task was to translate clinical descriptions to numerical form. This led to the publication in 1974 of what came to be known as the Glasgow Coma Scale(GCS). ${ }^{22}$ In that paper we referred to 14 previously published descriptions of altered consciousness, involving 3 to 17 different levels.

Because this was an international study we made every effort to select terms that could be easily understood by doctors, nurses and others, and not only those who were experts and also by those for whom English was not their first language. We avoided terms that were difficult to define such as describing motor responses as purposeful, semipurposeful, voluntary, brisk or slow. Also rejected were some terms in common use such as somnolent, obtunded, obnubliated, obstreperous and combative. Once a shortlist of terms was agreed we tested the inter-observer reliability of alternatives by having observers use them to describe responses in patients at the bedside or on video recordings. ${ }^{24}$ Later studies in several countries have confirmed the robustness of this tool for describing patients with altered consciousness, although two recent British reports found disagreements between observers, perhaps due to inadequate training. ${ }^{1,15}$ A feature of several previous systems was defining a level of consciousness by the simultaneous occurrence of responses in more than one domain when in practice one or other of these may be untestable. The essence of the GCS is the independent assessment of graded responses in three behavioral domains - eye opening (E), motor response (M) and verbal activity (V) (Table 1). If one type of response is untestable, for example due to periorbital swelling or endotracheal intubation, the others are still available. Moreover changes in the level of responsiveness are readily displayed on a bedside chart (Figure 1), and this can lead to earlier detection of treatable complications.

\section{Scoring by Numbers}

Ascribing numbers to the various response levels (the higher the number the better the response) was proposed a year later in a paper concerned with statistical predictions of outcome from the early coma score. ${ }^{8}$ This also facilitates communication between doctors who can report a patient's state as E2, M4, V3. Establishing the statistical relationship between the early responsiveness and the outcome depended on summing the scores to give an overall coma score, ranging from 3 to 14 in this paper. The next year we

\section{Eye opening}

4. Spontaneous. Indicates arousal, not necessarily awareness

3. To speech. When spoken to - not necessarily the command to open eyes

2. To pain. Applied to limbs, not face where grimacing can cause closure

1. None.

\section{Motor response}

6. Obeys commands. Exclude grasp reflex or postural adjustments

5. Localises. Other limb moves to site of nailbed pressure

4. Withdraws. Normal flexion of elbow or knee to local painful stimulus

3. Abnormal flexion. Slow withdrawal with pronation of wrist, adduction of shoulder

2. Extensor response. Extension of elbow with pronation and adduction

1. No movement.

\section{Verbal responses}

5. Orientated. Knows who, where, when; year, season, month

4. Confused conversation. Attends \& responds but answers muddled/wrong

3. Inappropriate words. Intelligible words but mostly expletives or random

2. Incomprehensible speech. Moans and groans only - no words

1. None

Table 1. Glasgow Coma Scale with scores

included 'abnormal flexion' as an additional motor score and the score for fully alert then became $15 .^{23}$ We then proposed a definition of coma as no eye opening, not obeying commands and no recognizable words. By this definition all patients scoring seven or less are in coma but only half of those scoring eight are. It is important to realize that when a patient's state is described only by the total score there is a loss of information compared with having the numbers for $\mathrm{E}, \mathrm{M}$ and $\mathrm{V}$. This is because any given total score can be made up of several different combinations of $\mathrm{E}, \mathrm{M}$ and $\mathrm{V}$. In a recent intensive care study mortality ranged from $0-20 \%$ for patients scoring seven with various permutations of $\mathrm{E}, \mathrm{M}$ and $\mathrm{V}$ soon after admission. ${ }^{26}$ Nonetheless the score is a useful tool in triage for initial disposal and for guidelines that indicate that patients above or below a given score should go to certain hospital facilities or should have particular investigations or therapeutic interventions.

\section{Acceptance of the GCS}

What was devised as a research tool soon became part of everyday practice in many countries, adopted by doctors and nurses not only in neurosurgical and intensive care units but in other departments dealing with acute brain 


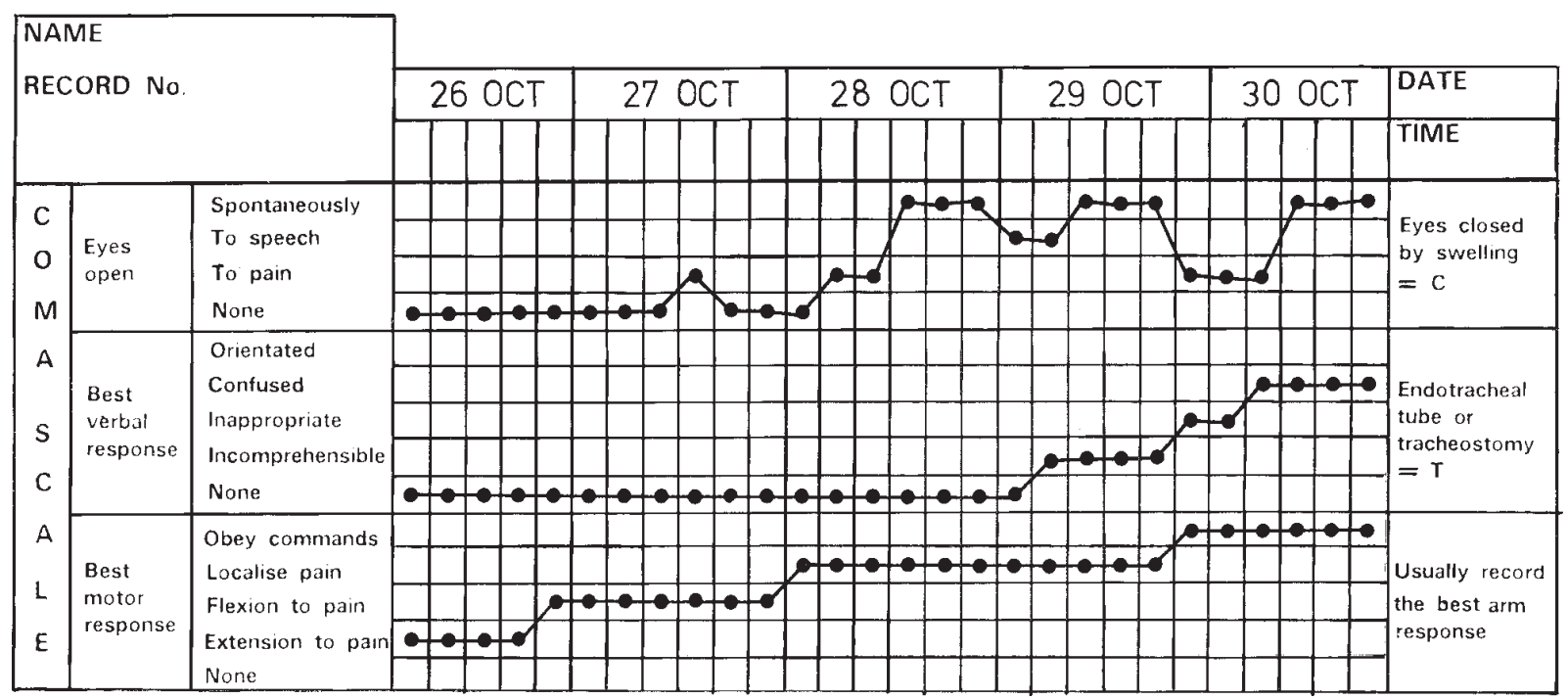

Figure 1. An early version of the bedside chart showing recovery from coma.

insults, traumatic and non-traumatic, as well as by emergency personnel involved in retrieving such patients. Its simplicity was attractive, and nurses particularly welcomed it because marking up the coma chart was similar to their customary recording of temperature, pulse and respiration. Indeed the year after the initial paper in the Lancet there were two papers from Glasgow in a nursing journal. ${ }^{19,20}$ It soon became part of nurse training and as they outnumbered doctors by 10 to 1 they were important in its dissemination as they moved around within and between hospitals. In 1978 an editorial by a leading American neurosurgeon recommended that both the GCS and the Glasgow Outcome Scale should be adopted by neurosurgeons for at least five years. ${ }^{11}$ It was not long before bodies sponsoring clinical research into traumatic and nontraumatic coma required applicants to submit patient data using these scales, and some claims for medical negligence have been based on the failure to use the coma scale as a bedside tool in the acute stage. By the year 2000 there were more than 1000 published references to its use, and university theses were devoted to analysis of its application. There were, however, some dissenters, most of whom considered that it was too simple but the various proposed alternatives were in turn criticized by the Glasgow team. ${ }^{21}$ There is, however, merit in adding the presence or absence of post-traumatic amnesia to the GCS when assessing mildly injured patients. ${ }^{5,16}$

\section{When to Assess the GCS for Prediction}

As a basis for monitoring progress after an acute insult the sooner the GCS is assessed the better. For predicting likely outcome, however, account must be taken of the many changes in responsiveness that commonly occur in the first 24 hours after an insult. In particular there may be rapid improvement as the effects of shock and hypotension, as well as of alcohol and other drugs subside. The most valid time to assess GCS for prognosis is therefore probably after resuscitation and stabilization, and if responses are variable it is the best response that most reliably relates to outcome. After resuscitation, however, many patients are often intubated and sedated, making assessment on the full scale then impossible. Clinicians vary in how they deal with this ${ }^{12,13}$ but the motor score alone can remain useful in such circumstances. Although there is a good correlation between early GCS scores and outcome it is important to consider other predictive features. A recent Glasgow study on head injury found that the patient's age, history of a lucid interval, pupil reactions and eye movements as well as initial CT findings were useful. ${ }^{17}$ In the APACHE III scoring system for use in general intensive care units the GCS has been found to be more predictive of the outcome than any other single variable. $^{2}$

\section{Applications of the GCS}

The original use of the GCS for classifying injury severity in multicenter studies has been followed by its use in many clinical trials of regimes and agents believed likely to improve outcome after acute brain insults. That has obviously been an application restricted to the small number of units involved in such studies. Of much more general use has been its adoption as a means of communication between different staff caring for such patients from the scene of the insult through to the intensive care unit. Improvements in monitoring for early signs of developing treatable complications has been an important consequence of its application, for studies showed that the commonest cause of avoidable mortality and morbidity after head injury was delay in the detection and hence the timely treatment of complications. Its use in devising guidelines for the management of acutely braindamaged patients has been mentioned. Beyond the field of care of such patients the GCS has been used to classify head injured patients in epidemiological studies worldwide. Three grades of severity are recognized, severe (GCS 8 or less), moderate (GCS 9-12, and mild (GCS 13-15). These show, for example, that only $5 \%$ of admitted head injuries are severe in developed countries, while over $80 \%$ are mild. ${ }^{4}$ This has resulted in increasing interest in mild injuries because they are so frequent, and because a substantial number of them 
develop complications resulting in death or disability. It is therefore important to consider the different prognostic features of patients assessed as GCS 13,14 and 15. Most important is the likelihood of brain damage being shown on CT scan, which increases the risk of complications. This is where it is useful to consider also whether or not the patient has any post-traumatic amnesia. ${ }^{5,16}$ It is important not to assume that because a patient is classified as only mildly injured he has not sustained any brain damage. In mildly injured patients who then develop complications it is important to distinguish between initial severity and ultimate severity. It is illogical, as some have suggested, to require as part of the definition of a mild injury that there should be no later complications. To do so would obscure the important fact that initially mild injuries frequently have complications. Indeed it is the hope of minimizing the damaging effects of these that informs the management of mild injuries by discovering which of them is at risk and should therefore be subjected to investigations and further observation.

\section{Before the Outcome Scale}

Soon after resuscitation and intensive care began to save the lives of severely brain damaged patients it was claimed that the survivors mostly would make a satisfactory recovery and return to productive work. That proved to be an overoptimistic speculation because many survivors suffer long lasting disability, the assessment of which is difficult because it is made up of both physical and mental deficits. The original publication of the Outcome Scale (GOS) in $1975^{6}$ reviewed the terms already in use to describe survivors of severe head injuries. One report classified them only as vegetative or recovered, whilst another recognized vegetative, persistent dementia or mental restitution. This last category included those with physical disability if they were 'able to participate in active rehabilitation'. This reflected a natural tendency for those who had worked so hard to secure the survival of these patients to make the best of their outcome. Among those classified as excellent in another series were patients with hemiplegia if they were 'fully active'. Terms such as 'practical', 'useful' or 'worthwhile' recoveries usually proved to be euphemisms for major persisting disability. It is of course easy in good faith to underestimate the degree of disability if this is based on only a brief outpatient encounter with a busy surgeon. This is because the most important disabilities are often mental deficits or personality change, which are revealed only by careful questioning of both the patient and his family.

\section{The Glasgow Outcome Scale}

The aim was to have a limited number of exclusive categories that summarized the social capacity of the patient rather than listing specific disabilities. The five categories were these:

Death. The only qualification to this relates to when the death occurs - usually it will be during the initial period in hospital, but it may be extended to those occurring within a specified time thereafter.

Persistent Vegetative State. This condition of unawareness with only reflex responses but with periods of spontaneous eye opening was described in $1972 .^{7}$ It is usually defined as present one month after a brain insult, and the word persistent is now usually dropped. Many patients who are vegetative at one month recover to a better category of outcome, emphasizing the need to state when the outcome has been assessed.

Severe Disability. This applies to a conscious patient who is dependent for daily support from another person by reason of mental or physical disability, usually a combination of both.

Moderate Disability. These patients have some disability such as dysphasia, hemiparesis or epilepsy and/or deficits of memory or personality but are able to look after themselves, do shopping and travel by public transport. They may be able to work when special arrangements are made.

Good Recovery. This implies a resumption of normal life with the capacity to work even if preinjury status has not been achieved. Some of these patients have neurological or psychological deficits.

\section{Number of Categories: When to Assess}

Some have complained that these categories are too broad and an extended scale has been proposed that divides each of the upper three levels into an upper and lower degree of disability. ${ }^{8,27}$ On the other hand when undertaking analysis of outcome for purposes of prediction and when comparing the outcome in clinical trials of treatment regimes it is usual to have fewer categories. Usually those with moderate disability or good recovery are regarded as having a satisfactory or 'good' outcome, while severe disability or vegetative survival is an unsatisfactory or 'poor' outcome. The use of this scale has recently been reviewed ${ }^{25,27}$ together with instructions on basing outcome assessment on a structured interview by various caregivers.

As to when to assess outcome this largely depends on the purpose for which this is being done. If mortality is the main measure sought then this may reasonably be assessed at the time of discharge from the facility providing acute care, as most deaths occur in the first week. For most purposes what is required is an estimate of the ultimate outcome, and note has to be taken of evidence that some patients continue to improve (or to adapt to their disability) over years. The problem is that maintaining follow-up over years is very difficult and in any event it is not practical to wait for years to record the outcome of trials of an acute condition. Studies have shown that most patients have reached their final point on the 5-point outcome scale by six months - which is not to deny that improvement within a category will not continue, nor that a small number of cases will improve their outcome category. ${ }^{8}$ For this reason many international studies are based on outcome at six months, which also proves to be an interval at which the majority of patients in a study can be successfully followed.

\section{Conclusions}

It is more than a quarter of a century since these two scales were introduced and they have been widely adopted in the management and study of patients with acute brain 
insults, both traumatic and non-traumatic. Indeed their availability has probably been a factor in encouraging the development of large numbers of studies of such patients. It is, however, important to emphasize the importance of adequate training of personnel in the proper use of these scales if their use is not to be potentially misleading.

\section{References}

1. Bassi S, Buxton N, Punt JA, et al: Glasgow coma scale: a help or hindrance. Br J Neurosurg 13:526, 1999

2 Bastos PG, Sun X, Wagner DP, et al: Glasgow Coma Scale score in the evaluation of outcome in the intensive care unit: findings from the Acute Physiology and Chronic Health Evaluation III study. Crit Care Med 21:1459-1465, 1993

3 Bates D, Caronna JJ, Cartlidge NEF, et al: A prospective study of non-traumatic coma: methods and results in 310 patients. Ann Neurol 2: 211-220, 1977

4. Jennett B: Epidemiology of head injury. J Neurol Neurosurg Psychiat 60: 362-369, 1996

5. Jennett B: The Glasgow Coma Scale: history and current practice. Trauma 4: 91-103, 2002

6. Jennett B, Bond M: Assessment of outcome after severe brain damage. Lancet 1: 480-484, 1975

7. Jennett B, Plum F: Persistent vegetative state after brain damage. Lancet 1: 734-737, 1972

8. Jennett B, Teasdale G: Management of Head Injuries. Philadelphia: FA Davis, 1981, pp 308-310

9. Jennett B, Teasdale G, Galbraith $\mathrm{S}$, et al: Severe head injuries in three countries. J Neurol Neurosurg Psychiat 40: 291-298, 1977

10. Jennett B, Teasdale G, Knill-Jones RP: Predicting outcome after severe head injury. J Roy Coll Physicians Lond 9: 231-237, 1975

11. Langfitt TW: Measuring the outcome from head injuries. J Neurosurg 48: 673-678, 1978

12. Livingstone BM, Mackenzie SJ, MacKirdy FN, et al: Should the pre-sedation Glasgow Coma Scale value be used when calculating the Acute Physiology and Chronic Health Evaluation scores for sedated patients? Crit Care Med 28:389-394, 2000

13. Marion DW, Carlier PM: Problems with initial Glasgow Coma Scale assessment caused by prehospital treatment of patients with head injuries: results of a national survey. J Trauma 36: 89-95, 1994
14. Medical Research Council Brain Injuries Committee: A glossary of psychological terms commonly used in cases of head injury. MRC War Memorandum No.4. London: His Majesty's Stationery Office, 1941

15. Morris K: Assessment and communication of conscious level: an audit of neurosurgical referrals. Injury 24:369-372, 1993

16. Nell V, Yates DW, Kruger J: an extended Glasgow Coma Scale (GCS-E) with enhanced sensitivity to mild brain injury. Arch Phys Med Rehabil 81: 614-617, 2000

17. Nissen JJ, Jones PA, Signorini DF, et al: Glasgow Head Injury Outcome Prediction Program: an independent assessment. J Neurol Neurosurg Psychiat 67:79699, 1999

18. Reilly PL, Adams JH, Graham DI, et al: Patients with head injury who talk and die. Lancet 2: 375-377, 1975

19. Teasdale G: Acute impairment of brain function -1 : assessing 'conscious level'. Nurs Times 71:914-917, 1975

20. Teasdale G, Galbraith S, Clarke K: Acute impairment of brain function -2 : observation record chart. Nurs Times 71: 972-973, 1975

21. Teasdale G, Gentleman D: The description of 'conscious level': a case for the Glasgow Outcome Scale. Scot Med J 27: 7-9, 1982

22. Teasdale G, Jennett B: Assessment of coma and impaired consciousness: a practical scale. Lancet 2:81-84, 1974

23. Teasdale G, Jennett B: Assessment and prognosis of coma after head injury. Acta Neurochir (Wien) 34: 45-55, 1976

24. Teasdale G, Knill-Jones R, van der Sande J: Observer variability in assessing impaired consciousness and coma. J Neurol Neurosurg Psychiat 41:603-610, 1978

25. Teasdale G, Laura EI, Pettigrew LEL, et al: Analyzing outcome of treatment of severe head injury: a review and update on advancing the use of the Glasgow Outcome Scale. J Neurotrauma 15:587-597, 1998

26. Teoh LSG, Gowardman JR, Larsen PD, et al: Glasgow Coma Scale: variation in mortality among permutations of specific total scores. Intens Care Med 26:157-161, 2000

27. Wilson JTL, Laura EL, Pettigrew LEL, et al: Structured interviews for the Glasgow Outcome Scale and the Extended Glasgow Outcome Scale: guidelines for their use. J Neurotrauma 15:573-585, 1998 